\title{
A EVOLUÇÃO DO DIREITO DE PROPRIEDADE AO LONGO DOS TEXTOS CONSTITUCIONAIS
}

\author{
PROPERTY RIGHTS IN THE CONSTITUTIONAL LEGAL HISTORY
}

\section{Luiz Gustavo Bambini de Assis*}

\begin{abstract}
Resumo:
O presente trabalho tem por tema a evolução do direito de propriedade, ao longo da história das constituições e, mais precisamente, das constituições brasileiras, no intuito de verificarmos de que maneira o Positivismo tratou esse direito fundamental de primeira dimensão.

Interessa, também, analisar a evolução do conceito de função social da propriedade, como e quando surge, e de que forma passa a limitar esse direito fundamental.

Palavras-chave: Direito de propriedade. Função social. Evolução constitucional.

Abstract:

This paper analyses the evolution of property right in the constitutional history, specially in the Brazilian constitutions, in order to identify how legal positivism concerned this first dimension fundamental right. Besides, an analysis of the origins of the concept of social function of property and its effectiveness in the limitation of the constitutional property right was made.
\end{abstract}

Keywords: Property right. Social function of property. Constitutional legal history.

\section{Tema}

O presente trabalho tem por tema a evolução do direito de propriedade, ao longo da história das constituições liberais burguesas, sociais e, mais precisamente, das constituições brasileiras, no intuito de verificarmos de que maneira o Positivismo tratou esse direito fundamental de primeira dimensão.

\section{Justificativa}

Um estudo que atente para a evolução do direito de propriedade na História da Civilização encontra sua importância na medida em que esse direito é, ainda hoje, garantido pelos textos constitucionais, mais precisamente pela Constituição-Cidadã, de 1988. Aplicá-lo às questões fáticas pressupõe sua análise evolutiva, até mesmo para melhor sopesá-lo e situá-lo ante a existência de novas dimensões de direitos fundamentais.

\footnotetext{
* Graduado e Mestre em Direito do Estado pela Faculdade de Direito da Universidade de São Paulo. Atualmente é aluno do curso de doutorado da mesma instituição. Assessor do Professor Titular de Direito do Estado da Faculdade de Direito da Universidade de São Paulo, Enrique Ricardo Lewandowski, Ministro do Supremo Tribunal Federal.
} 
Não é novidade que a grande estratégia da interpretação no sistema positivado moderno consiste no sopesamento de direitos fundamentais, sempre que uma situação de fato implicar a necessidade de se analisar a densidade de cada um desses direitos em um caso concreto. A unidade constitucional consiste justamente nessa necessidade constante de os intérpretes sopesarem direitos do mesmo calibre, quando analisados especificamente sobre a ótica do Direito positivado. ${ }^{1}$ Assim sendo, até para compreendermos a dinâmica do Direito, entendemos importante a análise da evolução do conceito de direito de propriedade principalmente na história do Direito Constitucional brasileiro.

\section{O surgimento do conceito de direito de propriedade}

Não é exagero afirmarmos que a propriedade nasce junto com o indivíduo, quase como algo inato do ser humano. Mais do que como um fenômeno jurídico, podemos caracterizá-la como um fenômeno social, por sua vez abraçado pelo Direito. O conceito de propriedade desenvolve-se quase que conjuntamente com a transição da fase do homem selvagem para a do homem sedentário, quando a civilização assenta-se sobre determinados espaços físicos, retirando da terra seu sustento e valores.

O poder ideológico do detentor da propriedade, ainda nos primórdios da civilização humana, fica evidente com o surgimento dos clãs religiosos, onde a figura do chefe de família (depois, pater famílias para o Direito Romano) tem destaque e liderança sobre as demais pessoas fixadas em um território.

Tanto o Império grego como o Império romano implicaram a eventual liderança ideológica e, posteriormente, econômica ao conceito de propriedade. Tanto é verdade que os jurisconsultos romanos trazem à tona o conceito de direito de propriedade como algo absoluto, indisponível, quase uma garantia fundamental do indivíduo. ${ }^{2}$

Interessante notar que a visão da propriedade como algo absoluto passa incólume também durante o período da Idade Média, quando o direito de propriedade é mantido inclusive como condição de manutenção da divisão social, havendo uma concentração imobiliária nas mãos de poucos que detinham certo poder social sobre

\footnotetext{
BARROSO. Luís Roberto. Interpretação e aplicação da Constituição. 6. ed. São Paulo: Saraiva, 2006. p. 196. Ao enaltecer o Princípio da Unidade da Constituição, ressalta que "É precisamente por existir pluralidade de concepções que se torna imprescindivel a unidade de interpretação. Afinal, a Constituição não é um conjunto de normas justapostas, mas um sistema normativo fundado em determinadas idéias que configuram um núcleo irredutível, condicionante da inteligência de qualquer de suas partes. O princípio da unidade é uma especificação da interpretação sistemática, e impõe ao intérprete o dever de harmonizar as tensões e contradições entre normas". (grifo nosso)

2 GROSSI, Paolo. La propriedad y las propriedades: um Análisis Histórico. Madrid: Editorial Civitas, 1992. p. 31-32. Ao analisar a propriedade sobre esse aspecto, ressalta que é justamente o ordenamento jurídico que dá a ela esse caráter estanque, fazendo com que esse instituto se converta em modelo supremo de validade.
} 
os demais indivíduos. Nas palavras do professor Caio Tácito, é nesse período que a propriedade ganha um contorno mais próprio dado pelo Direito:

Embora o Direito Romano não ofereça um conceito explícito da propriedade, os juristas da Idade Média foram colher em fragmento do Digesto o princípio essencial do aspecto dominante da senhoria a se exprimir na faculdade de usar, fruir e dispor da coisa como um direito subjetivo que se opõe a terceiros, obrigados a respeitá-los (jus utendi, fruendi e disponendi). ${ }^{3}$

Tornou-se imperioso regulamentar tal direito durante esse período, haja vista ser a concentração de terras o instrumento imprescindível para a manutenção do poder. Essa concentração de propriedade é motivo de fortalecimento, inclusive, das monarquias absolutistas que surgem com o advento da Idade Moderna, onde o poder e prestígio dos Reis poderia ser medido em virtude do que possuía cada Reino. A conquista de novas terras e até mesmo a usurpação do direito de propriedade alheio era condição para o fortalecimento do poder real que surgia com maior força.

\section{A positivação do direito de propriedade}

Os ideais liberais que sopraram sobre a Europa e América, principalmente a partir da transição da Idade Média para a Idade Moderna, trouxeram à tona o questionamento da concentração de direitos individuais por parte dos pensadores iluministas que povoaram esses territórios, principalmente, ao longo dos séculos XVII e XVIII.

O Iluminismo, pautado em suas duas correntes fundamentais, o racionalismo e o empirismo, levou à criação de duas importantes vertentes para a positivação do direito de propriedade. De um lado a vertente do contratualismo, cuja doutrina básica previa não ser o Estado fruto do acaso, mas resultado da ação racional do homem. A visão de Locke, Hobbes ${ }^{4}$ e Rousseau, dentre outros, de que o homem era detentor de direitos e que os levavam para a vida em sociedade foi decisiva para a cristalização dessa vertente na História da Humanidade. De outro lado, havia a vertente jusnaturalista, que buscou justamente positivar os direitos fundamentais e individuais que seriam anteriores à sociedade e ao Estado, cabendo a este respeitá-los.

É Locke quem preconiza, em um primeiro momento quais direitos fundamentais individuais deveriam ser positivados, no que podemos aqui denominar de

\footnotetext{
TACITO, Caio. Temas de direito público. Rio de Janeiro: Renovar, 1997. p. 581.

4 RIBEIRO, Renato Janine. Hobbes: o medo e a esperança. In: WEFFORT, Francisco C. Os clássicos da Política. 12. ed. São Paulo: Ática, 1986. p. 53. Para Hobbes, a origem do estado e/ou da sociedade está em um contrato - os homens viveriam naturalmente sem poder e organização - que somente surgiria depois de um pacto firmado por eles, estabelecendo as regras de convívio social e de subordinação política. Essa é a visão do contratualismo, ou seja, a organização política da sociedade e do estado.
} 
"passagem" do estado de natureza para o estado contratual. ${ }^{5}$ Assim, o direito de propriedade ganha um contorno maior a partir da teoria contratualista. Essa positivação ocorre com o surgimento da Carta Constitucional norte-americana, oriunda da Convenção de Filadélfia, de 1787, e na Declaração dos Direitos do Homem e do Cidadão, de 1789, na França. A partir dessas Cartas constitucionais, a incolumidade do direito de propriedade passa por gerações, sendo considerado um direito absoluto, imprescritível, inalienável.

Embora essa noção de direito absoluto tenha sido posteriormente contestada, ${ }^{6}$ é cediço que nenhuma lei maior dispensou dar à propriedade seu devido tratamento constitucional, positivando-o como universal. O que se pode constatar, a partir da análise das constituições acerca do tema, é que houve certa flexibilização desses direitos frente ao surgimento de novos direitos, posteriormente positivados como constitucionais.

É que, após as revoluções liberais do séc. XVIII, sobrevieram novos fatos históricos na trajetória das civilizações que mudaram, de certa forma, o paradigma de formulação de direitos fundamentais. A passagem da Idade Moderna para a Contemporânea é marcada pelo processo de Revolução Industrial, onde o modelo econômico capitalista, embora prospere na relação capital/trabalho das fábricas, conflita-se com o modelo socialista que se desenvolve no Leste da Europa, fortalecido com os movimentos sindical/anarquistas dessa era. Nesse período há uma contestação da idéia de que o direito de propriedade é absoluto, sendo dado, desde então, novo tratamento constitucional à questão. ${ }^{7}$

\footnotetext{
5 "O estado de natureza era, segundo Locke, uma situação real e historicamente determinada pela qual passara, ainda que em épocas diversas, a maior parte da humanidade e na qual encontra-se ainda alguns povos, como as tribos norte-americanas. Esse estado de natureza diferia do estado de guerra Hobbesiano, baseado na insegurança e na violência, por ser estado de relativa paz, concórdia e harmonia. Neste estado pacifico os homens já eram dotados de razão e desfrutavam da propriedade (grifo nosso) que, numa primeira acepção genérica utilizada por Locke, designava simultaneamente a vida, a liberdade e os bens como direitos naturais do ser humano". (MELLO, Leonel Itaussu Almeida. John Locke e o individualismo liberal. In: WEFFORT, Francisco. Os clássicos da Política. 12. ed. São Paulo: Ática, 1986. p. 85.

6 SILVA, José Afonso da. Comentário contextual à Constituição. 3. ed. São Paulo: Malheiros, 2007. p. 117. Assim explicita o Autor: "Demais, o caráter absoluto do direito de propriedade, na concepção da Declaração Universal dos Direitos do Homem e do Cidadão de 1789 (segundo a qual seu exercício não estaria limitado senão na medida em que ficasse assegurado aos demais indivíduos o exercício de seus direitos) foi sendo superado pela evolução, desde a aplicação da teoria do abuso do direito, do sistema de limitações negativas e depois também de imposições positivas, deveres e ônus, até chegar-se à concepção de propriedade como função social, e ainda à concepção de propriedade socialista, hoje em crise".

7 MIRANDA, Jorge. Manual de direito Constitucional. Direitos fundamentais. Portugal: Coimbra Editora, 2000. tomo IV, v. 3, p. 523. Afirma justamente nesse sentido: "Nas constituições liberais, como se sabe, ele (o direito de propriedade) surge a par da liberdade e da segurança como componente da sua idéia de direito; ou é considerado uma liberdade tão cuidadosamente protegida como as restantes. Já em constituições de tendências sociais, ainda quando não se dissocia dos direitos fundamentais, fica condicionado por outros interesses e valores da ordem econômica e posto a serviço de uma função social. E nas constituições do tipo soviético fica reduzida aos bens que dele positivamente podem ser objecto e reduzido na sua força preceptiva perante a lei e a administração".
} 
5. O direito de propriedade e seu tratamento constitucional ao longo do século XX

Ressaltamos no item anterior que a positivação da propriedade como um direito absoluto encontra respaldo nos movimentos liberais que culminaram na elaboração das constituições francesas, de 1789 e norte-americana, de 1787. Afirmamos também que esse caráter absoluto passa a ser relativizado. Resta-nos saber quando. A resposta é fruto, justamente, das transformações oriundas da Revolução Industrial e das teorias socialistas da época. O triunfo da Revolução Soviética, de 1917, e o surgimento do Estado de Weimar, pós- $1^{\circ}$ Guerra Mundial reformulam o conceito de direito de propriedade.

Não seria exagero anotarmos que tanto a Constituição mexicana, de 1917, quanto a Constituição de Weimar, de 1919, dão um novo tratamento para o conceito de direito de propriedade, tratamento esse que faz com que aquela deixe de ser vista apenas como um direito, passando a ser concebida também como uma obrigação, no sentido de que a propriedade obriga seu detentor a mantê-la. ${ }^{8}$

A Constituição portuguesa, de 1976, arrola o direito de propriedade no rol dos direitos econômicos, sociais e culturais, retirando-o do elenco dos direitos e liberdades individuais. Trata-se de uma nova visão deste direito, inclusive com uma dimensão de que esta passa a ser um instrumento de trabalho voltado para a questão distributiva.

Assim, podemos constatar um novo tratamento constitucional ao conceito, tratamento esse que, repetimos, relativisa o direito de propriedade frente aos novos direitos sociais que passam a ser constitucionalizados, e que exigem do estado uma ação positiva para a sua promoção. Um novo modelo estatal é desenhado. Esse modelo pressupõe não mais a omissão do Estado na defesa dos direitos fundamentais, mas sua promoção por meio das políticas e serviços públicos. Nesse contexto, o direito de propriedade, embora ainda considerado uma garantia fundamental, adquire uma nova dimensão e necessita adequarse à evolução social e política que leva à reformulação dos textos constitucionais. ${ }^{9}$

\footnotetext{
${ }^{8}$ Assim explicitava o art. 153 da Constituição de Weimar: "A propriedade obriga. Seu uso deve, ao mesmo tempo, servir ao bem-estar social".

9 RENNER, Karl. The institutions of private law and their Social Functions. (Trad. Agnes Schwarzchild). Routledge \& Kegan Paul, London: 1949. p. 75. Advém desse período o conceito de função social como algo amplo, não aplicável especificamente ao direito de propriedade. A discussão acerca dos efeitos de um instituto jurídico sobre a sociedade pode levar, de certa forma, à relativização deste em nome do bem-estar social. A idéia de autonomia do conceito função social em relação à norma que positiva o direito dá a dimensão do novo conceito que terá o instituto jurídico da propriedade a partir dessa nova visão de Estado, também voltado para a promoção do bem-estar.
} 


\section{A evolução constitucional do direito de propriedade no sistema brasileiro}

A questão da propriedade no Brasil sempre fora tratada de forma concentradora e desigual. Desde a instituição do regime das sesmarias, o seu processo de distribuição sempre foi aleatório e privilegiou os interesses da Coroa e daqueles a ela ligados por traços sociais e até mesmo de afetividade. ${ }^{10}$ Esse modelo de privilégios prevaleceu durante todo o período colonial $^{11} \mathrm{e}$, porque não ressaltar, também durante o Brasil Império e Republicano. Não é de se espantar que a propriedade tenha adquirido um caráter tão absoluto na nossa história.

Importa-nos agora reafirmar de que maneira as constituições nacionais absorveram o direito de propriedade em seus textos. Antes de mais nada, não é demais frisar que nossas constituições são também fruto das tendências sociológicas e políticas que sacudiram o mundo ao longo da História das civilizações. Fomos diretamente influenciados pelas teorias liberais e socialistas. Sem sombra de dúvidas essas tendências aparecem em nossos textos constitucionais e, no que tange ao direito de propriedade, pode ser ainda mais explicitado.

Tanto a Constituição de 1824, como a de 1891 deram tratamento semelhante ao direito de propriedade. Influenciadas pelas constituições liberais americana, de 1787, e francesa, de 1789, tratando o direito de propriedade em toda a sua plenitude. ${ }^{12}$ Vale lembrar ainda, de maneira muito breve, a criação de instrumentos normativos infraconstitucionais

\footnotetext{
${ }^{10}$ BERCOVICI, Gilberto. A Função Social da Propriedade. In: Constituição Econômica e Desenvolvimento, uma leitura a partir da Constituição de 1988. São Paulo: Malheiros, 2005. p. 119. "As características das sesmarias eram a gratuidade e a condicionalidade. As Ordenações determinavam que a concessão de terras fosse gratuita, sujeita apenas ao dízimo para a prorrogação da fé. O fato de o solo colonial pertencer à Coroa, sob jurisdição espiritual da Ordem de Cristo, garantiu a gratuidade da concessão".

${ }^{11}$ GOMES, Laurentino. 1808. São Paulo: Planeta, 2007. p. 148. Importante o relato trazido à baila pelo Autor ao descrever o que ocorreu com s propriedades da elite colonial com a chegada da Família Real ao Brasil. Segundo o Autor, "Mais complicado foi encontrar habitação para os milhares de acompanhantes da Corte, recém-chegados à cidade que ainda era relativamente pequena, com apenas 60.000 habitantes. Por ordem do Conde dos Arcos, criou-se o famigerado sistema de "aposentadorias", pelo qual as casas eram requisitadas para uso da nobreza. Os endereços escolhidos eram marcados na porta com as letras PR, iniciais de Príncipe Regente, que imediatamente a população começou a interpretar como "Ponha-se na Rua". Esse fato demonstra o descaso da Coroa com a consagração constitucional do direito de propriedade, declarado como fundamental pelas cartas Francesa e Americana. E, ao relembrar palavras do jornalista Hipólito da Costa, o Autor ressalta que "o sistema de aposentadorias era um regulamento "medieval", um "ataque direto ao sagrado direito de propriedade", que "poderia tornar o novo governo no Brasil odioso para o seu povo".

12 Assim dispunha o art. 179 da Constituição de 1824:

“Art. 179. A inviolabilidade dos Direitos Civis, e Políticos dos Cidadãos Brazileiros, que tem por base a liberdade, a segurança individual, e a propriedade, é garantida pela Constituição do Império, pela maneira seguinte:

XXII. É garantido o Direito de Propriedade em toda a sua plenitude. Se o bem publico legalmente verificado exigir o uso, e emprego da Propriedade do Cidadão, será elle préviamente indemnisado do valor della. A Lei marcará os casos, em que terá logar esta unica excepção, e dará as regras para se determinar a indemnisação."
} 
que vigeram após as constituições, de 1824 e 1891. A Lei de Terras, de 1850, por exemplo, trouxe importantes inovações no que se referia à necessidade de produtividade da terra para revalidação do título de posse ou propriedade. ${ }^{13}$ Assim também o Código Civil, de 1916, inovou ao tratar da relação jurídica do direito de propriedade, embora tenha ratificado o direito de uso e fruição da propriedade de forma indistinta.

Mudança radical de paradigma traz a Constituição, de 1934, haja vista que o Governo oriundo da Revolução de 1930 rompia quase que totalmente com a visão de Estado mantida durante o período da República Velha. Assim, com o advento de um Estado social, também resultado das revoluções sociais do início do século, e seguindo uma tendência das constituições mexicana e de Weimar, surge a idéia de que o direito de propriedade não pode ser exercido contra o interesse social ou coletivo. ${ }^{14}$

A Constituição outorgada, de 1937, restringe completamente o direito de propriedade aos termos da Lei, centralizando esse conceito e a disciplina desse direito nas mãos do presidente da República. ${ }^{15} \mathrm{O}$ próprio conteúdo do direito de propriedade é desconstitucionalizado, passando a questão a ser tratada por leis inferiores. Data do período do Estado novo por meio de importantes instrumentos normativos como o Decreto-Lei n. 3.365/1941, Lei da Desapropriação, que, inclusive, condiciona as possibilidades de desapropriação para fins de utilidade pública.

\footnotetext{
A questão da indenização por parte da usurpação do direito pelo Estado, como se vê, era a única condicionalidade para a perda desse direito. No mesmo sentido encaminhou-se a Constituição de 1891, em seu art. 72:

"Art 72 - A Constituição assegura a brasileiros e a estrangeiros residentes no País a inviolabilidade dos direitos concernentes à liberdade, à segurança individual e à propriedade, nos termos seguintes:

$\S 17$ - O direito de propriedade mantém-se em toda a sua plenitude, salva a desapropriação por necessidade ou utilidade pública, mediante indenização prévia."

13 Assim dispunha o art. $4^{\circ}$ da Lei 601, de 18.09.1850

“Art. $4^{\circ}$ Serão revalidadas as sesmarias, ou outras concessões do Governo Geral ou Provincial, que se acharem cultivadas, ou com princípios de cultura, e morada habitual do respectivo sesmeiro ou concessionário, ou do quem os represente, embora não tenha sido cumprida qualquer das outras condições, com que foram concedidas".

14 Assim ditava o art. 113 da Carta Constitucional de 1934:

“Art 113 - A Constituição assegura a brasileiros e a estrangeiros residentes no País a inviolabilidade dos direitos concernentes à liberdade, à subsistência, à segurança individual e à propriedade, nos termos seguintes:

17) É garantido o direito de propriedade, que não poderá ser exercido contra o interesse social ou coletivo, na forma que a lei determinar. A desapropriação por necessidade ou utilidade pública far-se-á nos termos da lei, mediante prévia e justa indenização. Em caso de perigo iminente, como guerra ou comoção intestina, poderão as autoridades competentes usar da propriedade particular até onde o bem público o exija, ressalvado o direito à indenização ulterior.

Há que se ressaltar aqui a nova visão dada ao direito de propriedade, que pela primeira vez pode vir a colidir com outros interesses (ainda não se falava em direitos) sociais.

15 Redação do art. 122 do art. 157 da Constituição de 1937:

“Art 122 - A Constituição assegura aos brasileiros e estrangeiros residentes no País o direito à liberdade, à segurança individual e à propriedade, nos termos seguintes:

14) o direito de propriedade, salvo a desapropriação por necessidade ou utilidade pública, mediante indenização prévia. O seu conteúdo e os seus limites serão os definidos nas leis que lhe regularem o exercício".
} 
O processo de redemocratização do País após o suicídio de Getúlio Vergas, em 1945, é coroado com a promulgação da Constituição Social, de 1946. Esta volta a inovar no que se refere ao conceito de direito de propriedade, conjugando-se o aspecto formal e material da vontade popular. O art. 141 traz a possibilidade da desapropriação por interesse social. Há ainda um importante avanço social no art. 147 que conjuga a idéia de propriedade e bem-estar social ${ }^{16}$.

A Constituição, de 1967, tenta ser o protagonismo do Estado como agente de desenvolvimento econômico. Embora centralizadora e autoritária, inova significativamente em relação ao direito de propriedade. Após a Emenda Constitucional n. 01/69 e o Ato Institucional n. 5, a propriedade (art. 153, § 22) estava garantida como um direito mas vem à tona a idéia de função social. É do período do regime militar instrumentos importantes como o Estatuto da Terra que traz restrições ao direito da propriedade em prol do desenvolvimento.

Verifica-se pois, que o direito de propriedade tem um tratamento evolutivo diferenciado pelos nossos textos constitucionais. De um direito absoluto e inquestionável, assim tratado pelas primeiras constituições brasileiras, passa a ser paulatinamente relativizado, ficando atrelado à idéia de bem-estar social, desenvolvimento, até se chegar ao hodierno conceito de função social da propriedade.

7. A Constituição de 1988, a noção de função social e as limitações ao direito de propriedade

Vários são os artigos da Carta Magna que tratam do direito de propriedade. Sem sombra de dúvida, é o art. 170 que traz a maior inovação sobre o conceito, ao dispor sobre a ordem econômica e financeira. Isso porque a livre iniciativa e a valorização do trabalho humano, primórdios da justiça social no País, devem atender ao princípio da propriedade privada e respeitá-la. Todavia, ao mesmo tempo que esse comando está previsto no inciso II do citado artigo, seu inciso III trata justamente de positivar o conceito de função social da propriedade, também tratado no inciso XXIII do art. $5^{\circ}$ da Carta Constitucional como requisito para a garantia do direito de propriedade.

Por ser uma Constituição extremamente complexa e abranger uma série de direitos sociais e difusos, tornou-se necessária uma interpretação mais interativa do

\footnotetext{
16 Constituição de 1946, art. 141:

"Art 141 - A Constituição assegura aos brasileiros e aos estrangeiros residentes no País a inviolabilidade dos direitos concernentes à vida, à liberdade, a segurança individual e à propriedade, nos termos seguintes:

$\S 16$ - É garantido o direito de propriedade, salvo o caso de desapropriação por necessidade ou utilidade pública, ou por interesse social, mediante prévia e justa indenização em dinheiro. Em caso de perigo iminente, como guerra ou comoção intestina, as autoridades competentes poderão usar da propriedade particular, se assim o exigir o bem público, ficando, todavia, assegurado o direito a indenização ulterior”.
} 
texto constitucional, cotejando-se diferentes princípios a serem sopesados diante de um fato concreto. ${ }^{17}$ Mais do que isso, o art. 173 trouxe uma série de limitações ao direito de propriedade como a servidão, a ocupação temporária, a requisição, além da já prevista desapropriação. ${ }^{18}$ Todas essas limitações ao direito de propriedade evidenciam que esse não é mais um direito absoluto, e que necessita ser cotejado não apenas com outros direitos constitucionais fundamentais, mas também com o interesse público e as necessidades do Estado moderno.

8. Conclusão

A propriedade nasce como um conceito absoluto. É assim positivada pelas primeiras constituições da História das civilizações, que declaram o direito de propriedade como um direito natural do ser humano.

No Brasil, o primeiro tratamento constitucional do direito de propriedade segue essa vertente, e as constituições, de 1824 e 1891, dão esse caráter absoluto à

17 Interessante verificarmos a evolução jurisprudencial do tema. Analisando o RE 178.836-4/SP, de 08/06/1999, cujo relator foi o Min. Carlos Velloso, onde se discutia o direito do proprietário edificar bem residencial em área considerada comercial por lei municipal, podemos constatar que o direito de propriedade é relativizado ante a competência constitucional do Município de editar leis de zoneamento local. Em seu voto vista, o Min. Maurício Correia trata especificamente do caráter absoluto do direito de propriedade na nova ordem constitucional:

"Ora, como é sabido, o direito de propriedade não é absoluto. Consoante preconiza a carta da República, a propriedade atenderá à sua função social, inserindo-se nesse conceito o cumprimento dos ditames da política de desenvolvimento urbano, executada pelo poder público municipal, conforme diretrizes gerais fixadas em lei".

Em outro interessante julgado do STF, MS 22.164-0/SP, de 30/10/1995, Rel. Min. Celso de Melo, o direito de propriedade e sua função social são cotejados com o direito difuso de preservação do meio ambiente. Interessante notar que o Relator faz alusão direita ao cumprimento da função social, atrelando-o à necessidade de defesa do meio ambiente:

"A própria Constituição da república, ao impor ao poder público o dever de fazer respeitar a integridade do patrimônio ambiental, não o inibe, quando necessária a intervenção estatal na esfera dominial privada de promover a desapropriação de imóveis rurais para fins de reforma agrária, especialmente porque um dos instrumentos de realização da função social da propriedade consiste, precisamente, na submissão do domínio à necessidade de o seu titular utilizar adequadamente os recursos naturais disponíveis e de fazer preservar o equilíbrio do meio ambiente (CF, art. 186, III), sob pena de, em descumprindo esses encargos, expor-se à desapropriação sanção a que se refere o art. 184 da Lei Fundamental".

Tratava-se da necessidade de se desapropriar área rural que não respeitava as regras ambientais, sendo que nesse caso, mais uma vez, o direito de propriedade foi cotejado com outro direito também constitucionalmente fundamental que é o direito à preservação do meio ambiente. Nesse caso, a função social da propriedade exigiria o respeito às normas ambientais.

18 TACITO, Caio. op. cit. p. 583. O Autor, ao afirmar que o conceito de direito de propriedade é, de alguma forma, relativizado após a Constituição, de 1988, porquanto esta "incorpora ao plano superior da hierarquia normativa a tendência que vem acentuando a partir da década de 70, de submeter o uso da propriedade imobiliária ao planejamento das cidades". A partir dessa constatação e do julgado ementado nos autos do RE 178.836-4/SP já citado, resta evidente a subordinação daquele conceito absoluto de propriedade à necessidades modernas, como a de organização planejada dos centros urbanos. 
propriedade. Vale ressaltar que no interregno dessas constituições já há um tratamento diferenciado a ser dado à propriedade pela Lei de Terras, de 1850.

A Constituição, de 1934, por sua vez é a primeira a atrelar o conceito de direito de propriedade à promoção do bem-estar social, limitando-o minimamente. Porém, ao desconstitucionalizar o direito de propriedade, a Constituição, de 1937, concentra os poderes nas mãos do presidente da República para sobre ele dispor.

A redemocratização de 1946 traz à tona novamente a idéia de que a propriedade deve estar voltada para o desenvolvimento social, e seu caráter absoluto, felizmente, não volta a ser constitucionalizado. A noção de função social porém só nasce após a emenda constitucional feita à Constituição de 1967, mas é verdadeiramente positivada a partir da Constituição de 1988.

Como vimos, o direito de propriedade tem diferenciados tratamentos constitucionais ao longo de sua história. Hodiernamente, é sopesado face à existência de outros direitos do mesmo quilate que com ele podem se confrontar. Não poderia ser diferente em uma sociedade moderna e democrática, onde a garantia de direitos de todas as dimensões devem ser respeitadas, não mais prevalecendo a lógica liberal burguesa do direito como única fonte de inspiração do processo interpretativo.

São Paulo, dezembro 2008.

\section{Referências}

BARROSO, Luís Roberto. Interpretação e aplicação da Constituição. 6. ed. São Paulo: Saraiva, 2006.

BERCOVICI, Gilberto. A função social da propriedade, constituição econômica e desenvolvimento, uma leitura a partir da Constituição de 1988. São Paulo: Malheiros, 2005.

GOMES, Laurentino. 1808. São Paulo: Planeta, 2007.

GROSSI, Paolo. La propriedad y las propriedades: um Análisis histórico. Madrid: Editorial Civitas, 1992.

MELLO, Leonel Itaussu Almeida. John Locke e o individualismo liberal. In: WEFFORT, Francisco. Os clássicos da Política. 12. ed. São Paulo: Ática, 1986.

MIRANDA, Jorge. Manual de direito constitucional. Direitos fundamentais. Coimbra: Coimbra, 2000. tomo IV, v. 3.

\section{PRESIDÊNCIA DA REPÚBLICA}

http://www.planalto.gov.br/ccivil_03/Leis/principal_ano.htm 
RENNER, Karl. The institutions of private law and their Social Functions. Tradução de Agnes Schwarzchild). London: Routledge \& Kegan Paul, 1949.

RIBEIRO, Renato Janine Ribeiro. Hobbes: o medo e a esperança. In: WEFFORT, Francisco C. Os clássicos da Política. 12. ed. São Paulo: Ática, 1986.

SILVA, José Afonso da. Comentário contextual à Constituição. 3. ed. São Paulo: Malheiros, 2007.

\section{SUPREMO TRIBUNAL FEDERAL}

http://www.stf.gov.br/jurisprudencia/IT/in_processo.asp?origem $=\mathrm{IT} \&$ classe $=\&$ processo $=178836 \&$ recurso $=0 \&$ tip_julgamento $=\mathrm{M}$

http://www.stf.gov.br/jurisprudencia/IT/in_processo.asp?origem=IT\&classe=\&processo=22164\&r ecurso $=0 \&$ tip_julgamento $=\mathrm{M}$

TACITO, Caio. Temas de direito público. Rio de Janeiro: Renovar, 1997. v. 1. 